\title{
Tax Rate Cuts and Tax Compliance- The Laffer Curve Revisited
}

\author{
Tamás K. Papp and Elöd Takáts
}





\title{
IMF Working Paper
}

\author{
Policy Development and Review Department \\ Tax Rate Cuts and Tax Compliance- \\ The Laffer Curve Revisited ${ }^{1}$
}

\section{Prepared by Tamás K. Papp and Előd Takáts}

Authorized for distribution by Marianne Schulze-Ghattas

January 2008

\begin{abstract}
This Working Paper should not be reported as representing the views of the IMF.

The views expressed in this Working Paper are those of the author(s) and do not necessarily represent those of the IMF or IMF policy. Working Papers describe research in progress by the author(s) and are published to elicit comments and to further debate.

The paper shows how tax rate cuts can increase revenues by improving tax compliance. The intuition is that tax evasion has externalities: tax evaders protect each other, because they tie down limited enforcement capacity. Thus, relatively small tax rate cuts, which decrease incentives to evade taxes, can lead to increased revenues through spillovers - creating Laffer effects. Interestingly, tax rate cuts here imply increasing effective taxes. The model is consistent with what happened in Russia, and may provide basis for further thinking about tax rate cuts in other countries.

JEL Classification Numbers:H2, H26

Keywords: tax evasion, tax compliance, Laffer curve

Author’s E-Mail Address: etakats@imf.org

\footnotetext{
${ }^{1}$ The authors are grateful for Gary Becker, Péter Benczur, Stijn Claessens, Ketil Hviding, Michael Keen, Alexander Klemm, István Székely and seminar participants at Princeton University and the International Monetary Fund for their comments. All remaining errors are ours.
} 


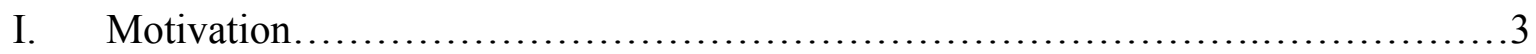

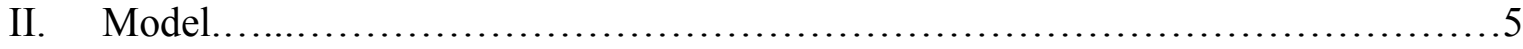

A. Endogenous enforcement............................................... 6

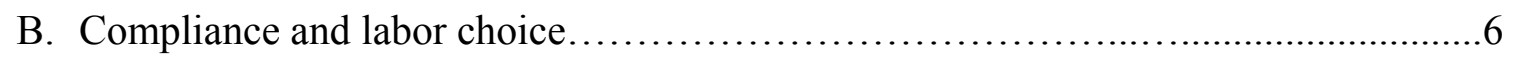

C. Equilibrium and comparative statics.....................................

III. Illustrative example......................................................... 10

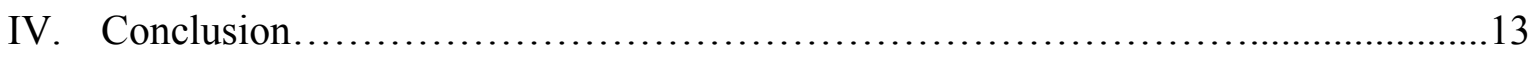

V. Appendix.............................................................. 17

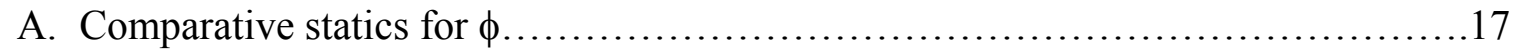

B. Multiple equilibria ......................................................

Text Figures

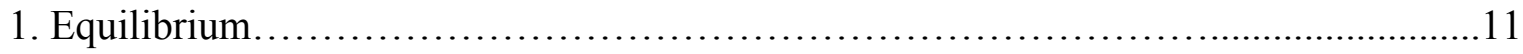

2. Tax rate change: 1 percent................................................. 12

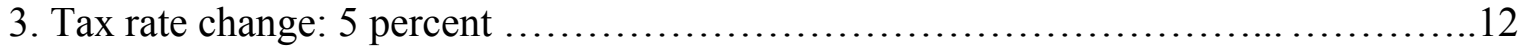

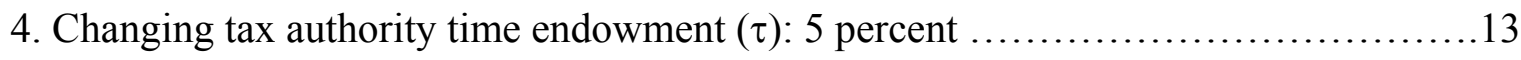

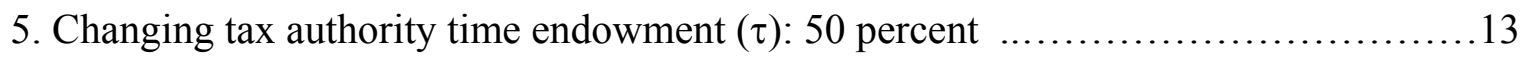

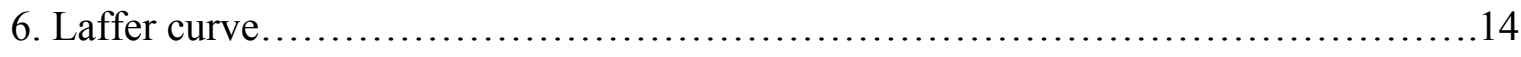

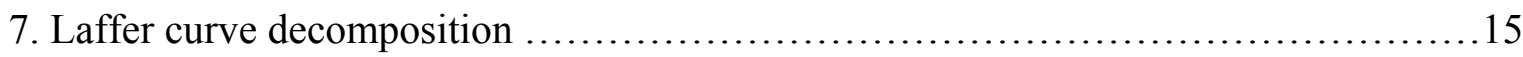

8. Multiple equilibria..................................................... 18

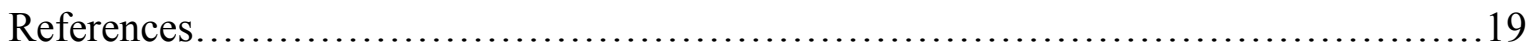




\section{Motivation}

Can tax rate cuts increase revenues? The question has been recurring in tax policy discussions from the United States to other developed and emerging economies. The Russian flat tax experiment is particularly interesting: after the introduction of flat taxes, and effective personal income tax rate cuts, tax revenues increased substantially and almost immediately. Furthermore, they increased much faster than labor supply and output. The paper explains how tax rate cuts can increase tax revenues through tax compliance spillovers in such a manner.

Tax compliance issues are widespread and are of general interest. Even in the United States, with its sophisticated tax enforcement mechanisms, the IRS (2006) estimated the federal tax gap to reach US\$ 345 billion or $16.3 \%$ of total revenues in 2001. Tax gaps and compliance problems might be even more relevant in other countries. This paper identifies the theoretical conditions under which tax rate cuts can increase compliance sufficiently to increase tax revenues.

To illustrate the potential effects of tax rate cuts on tax revenues consider the example of Russia. Russia introduced a flat 13 percent personal income tax rate, replacing the three tiered, 12, 20 and 30 percent previous rates (as detailed in Ivanova, Keen and Klemm, 2005). The tax exempt income was also increased, further decreasing the tax burden. Considering social tax reforms enacted at the same time, tax rates were cut substantially for most taxpayers. However, personal income tax (PIT) revenues have increased significantly: 46 percent in nominal and 26 percent real terms during the next year. Even more interesting PIT revenues have increased from 2.4 percent to 2.9 percent of GDP - a more than 20 percent increase relative to GDP. PIT revenues continued to increase to 3.3 percent during the next year, representing a further $14 \%$ gain relative to GDP. Furthermore, even official estimates showed increased tax compliance. ${ }^{1}$

This paper shows that endogenous tax compliance responses can be responsible for the massive increase in tax revenues. The key intuition is that tax regimes are prone to spillovers, as the aggregate behavior of taxpayers determines how much time the tax authority can dedicate to the individual taxpayer. In a way, tax evaders protect each other by tying down the tax authority's limited capacity. Hence, small cuts in the tax rates can lead to much larger changes in the behavior of taxpayers - most importantly, it can make them much more likely to declare their incomes honestly. These spillovers can lead to increasing tax revenues.

The paper builds a general equilibrium model with heterogenous taxpayers with endogenous tax audit probabilities. The model is set up in three steps. First, we endogenize the probability

${ }^{1}$ On one hand, those affected by the tax rate cuts (higher income taxpayers) improved their compliance, which is consistent with our model. On the other hand, Ivanova, Keen and Klemm (2005) also found that the unaffected had significant salary increases and the observed compliance increase does not explain revenue increase. However, in the light of this model, it would worth further studies to disentangle effects of higher wages from those of higher reported wages and higher compliance. Higher reported wages might be a consequence of unobserved increase in compliance. In any case, this model is not an empirical evaluation of what has happened in Russia, but a general theoretical exploration of tax rate cuts. 
of tax audits following Sah (1991) endogenous crime result. In the tax literature reviewed in Slemrod and Yitzhaki (2002) tax audit probabilities are taken exogenously. In our setup the tax authority has fixed time endowment to audit a unit volume of taxpayers. The fixed endowment incoproprates the long term capacity building needs of increasing the tax authority's effective resources. Auditing honest taxpayers is less time consuming than auditing tax evaders, as there is no need for prosecution. Hence, the more taxpayers evade taxes, the less likely it is that the tax authority can audit individual taxpayers. In short, the tax authority's limited capacity combined with auditing time differences creates the externality.

Second, we endogenize labor supply decisions into the decision of the taxpayer. In order to obtain a closed form solution, a linear quadratic model setup is chosen. ${ }^{2}$ Agents decide both about their labor supply and whether or not declare their income. Tax evaders who get caught pay due taxes and penalties proportional to the tax revenues evaded. ${ }^{3}$ In this setup, taxpayers evade less tax payments when the tax rate is lower, ceteris paribus. Intuitively, the gains from tax evasion drop faster than potential costs as the tax rate decreases. The result is supported by Clotfelter (1983) who finds empirically that evasion increases with the tax rate.

Third, we introduce heterogenous taxpayers, who differ in what we call shame, i.e. in their utility costs of punishment from public humiliation or prison sentences. ${ }^{4}$ Sufficient taxpayer heterogeneity ensures that tax changes result in continuous changes in tax revenues. ${ }^{5}$ Of course, "tax riots" (as in Bassetto and Phelan, 2006) can happen as responses to drastic measures, such as the British poll tax (see further in Besley et al, 1997). However, our focus is on the effects of minor changes in the tax rate through spillovers in compliance, without major changes in the perceived fairness of the tax regime.

The model demonstrates that even with relatively small labor supply responses tax rate cuts can increase equilibrium tax revenues significantly. The available data from the Russian flat tax

\footnotetext{
${ }^{2}$ Risk neutrality implied by the model setup is not fully innocuous. As shown in Allingham and Sandmo (1972) risk averse consumers might in fact increase tax evasion under certain circumstances. Intuitively, lower taxes imply higher income, and thus higher propensity to gamble for risk averse consumers.

${ }^{3}$ The literature (reviewed in Slemrod and Yitzhaki, 2002) distinguishes between two types of penalties: those proportional to tax revenues evaded and those proportional to income concealed. We choose the former as it is the weakest assumption we need: behavioral changes are, if anything, stronger if tax cuts do not also cut the punishment for evasion. Hence, our results are only stronger under the other assumption. The correct specification, however, might be relevant for calibrating the model, and it should be subject to further research.

${ }^{4}$ The specifications leads to qualitatively equivalent results to the one under which costs of evasion differ.

${ }^{5}$ The homogenous taxpayer setup could potentially lead to multiple equilibria as in the reputational model of Cowell (1990). Even the heterogenous agent model can produce multiple equilibria, as it is shown in the appendix.
} 
experiment is consistent with the results detailed here. In spite of the tax rate cuts the average effective PIT rate has increased from 11.2 percent to 11.8 percent suggesting higher compliance. Even official estimates have shown an increase in compliance from 72.4 percent to 74.0 percent. The estimates of Ivanova, Keen and Klemm (2005) show an even larger compliance effect for the affected group. Contradicting the traditional labor supply based explanations of the Laffer effect, measures of labor supply remained mostly unchanged.

Placing the tax evasion problem in a simple general equilibrium framework is useful for understanding the macroeconomic consequences of tax policy. First, it allows the joint investigation of taxes and other macroeconomic issues. The implications are not trivial: for instance, under standard RBC parameters the income effect of taxes dominates, thus consumers increase labor supply as a response to increased taxes. This is clearly inconsistent with what we know about the effects of tax increases. Second, the joint setup allows future calibrations to separately analyze labor supply (i.e. classical supply side) and compliance related effects of tax cuts.

The model can be used to sharply distinguish tax compliance effects from labor supply ones when thinking about the effects of tax cuts on tax revenues. Classical empirical studies like Heckman (1983) or Feldstein (1995) abstracted away from the compliance channel and focused entirely on the labor supply. Even the more recent Feldstein (2002) and the Fisman and Wei (2004) studies do not distinguish between the two effects when discussing the existence of the Laffer curve in alternative settings.

Finally, the model can be used to think about tax rate cuts and their effects. Most importantly, the tax compliance channel explored here provides a non-ideological tax rate cut rationale: tax rate cuts increase revenues by increasing the effective tax rate. This increase comes only at the expense of tax evaders, i.e. those who previously did not comply with the tax regime - and is not costly for law-abiding taxpayers. In fact, law abiding taxpayers' tax burden decreases while tax revenues increase. As a result policy makers might use the additional proceedings to cut taxes further or increase government spending at their discretion.

The paper is organized as follows. In the next section we set up the theoretical model in three steps. Second, we numerically explore the results and illustrate how tax cuts and tax enforcement measures work. Most importantly, we show that the Laffer curve can arise even with very small changes in labor supply effects.

\section{MODEL}

We investigate an economy populated by a unit volume of taxpayers. There is a single tax authority with limited resources, which audits taxpayers. The model is set up in three steps. First, we describe how tax enforcement works. Second, we introduce the maximization problem of the taxpayer, in particular the decisions on compliance and labor supply. Third, we introduce taxpayer heterogeneity and solve the model. 


\section{A. Endogenous enforcement}

Tax audits take time, and we assume that prosecuting tax evaders take more time than routine audits. Before auditing a taxpayer, the tax authority does not know whether she evaded taxes. A routine audit takes $\tau_{h}$ time ("honest"), while auditing and prosecuting a tax evader takes $\tau_{e}$ time ("evader"). We will assume that

$$
\tau_{e}>\tau_{h}
$$

i.e. that auditing and prosecuting tax evaders takes more time and effort than auditing honest taxpayers. The difference comes from many sources: preparing documentations for prosecution or trials, administering hearings, or undertaking prosecutions.

The total time endowment ("resources") of the tax authority is $\tau$, which we assume to be insufficient to audit the unit volume of honest taxpayers, i.e. $\tau<\tau_{h}$. In other words, the tax authority does not have enough time to audit all taxpayers, even if all of them are honest.

The timing is as follows:

1. Taxpayers select their strategy, which is not observed by the tax authority.

2. The tax authority audits taxpayers randomly until its time endowment is exhausted.

Using this setup, we define and derive two variables necessary to solve the model. Assuming that a fraction $\lambda$ of the population evades taxes, let $\mu$ denote the number of taxpayers the tax authority can audit before using up its time endowment. Then necessarily:

$$
\mu=\frac{\tau}{\lambda \tau_{e}+(1-\lambda) \tau_{h}}
$$

Note that $0<\mu<1$, because $\tau<\tau_{h}<\tau_{e}$.

Since the total mass of taxpayers is unity, $\mu$ is also the probability of being audited. Consequently, the probability that an individual taxpayer is audited is inversely related to the volume of tax evaders in the economy.

\section{B. Compliance and labor choice}

Next we turn to the decision problem of the tax payers. Taxpayers maximize utility

$$
u(c, \ell)=c-\frac{1}{2} A \ell^{2}
$$

where $c$ is consumption and $\ell$ is labor. Consumption is composed of (after-tax) income, where income is obtained using the linear production technology $y=\ell^{6}$

${ }^{6}$ To close the model, we could suppose that the government has to finance some fixed government expenditure $g$, with budget constraint

$$
\text { taxes }=g+\text { transfers }
$$


Taxpayers are required to pay a $\gamma<1 / 2$ fraction of their income $y$ in taxes. ${ }^{7}$ However, taxpayers will decide whether or not to pay the taxes. For tie breaking, we assume that indifferent taxpayers pay their taxes honestly:

$$
u_{e}>u_{h}
$$

Tax evaders do not pay taxes, but tax evasion requires a fixed effort (regardless of income level), which we denote by $E .^{8}$ Furthermore, we assume that if an agent is caught, she is required to pay taxes plus a punishment of $\pi \phi$ times taxes $\gamma y$. In this framework, $\pi$ is the "general" level of punishment for tax evasion, while $\phi$, which we interpret as the "shame" parameter, varies in the population: it is meant to capture the difference in the subjective utility weight that different taxpayers place on the same nominal punishment. For instance, some might perceive the humiliation of a prison sentence or a fine worse than others. ${ }^{9}$ We will denote the cross-sectional distribution of $\phi$ by $F$, and impose ${ }^{10}$

$$
\mathrm{E}[\phi]=1
$$

If the taxpayer pays taxes, $c=(1-\gamma) y$, and she solves

$$
\max _{\ell}(1-\gamma) \ell-\frac{1}{2} A \ell^{2}
$$

which yields

$$
\frac{1-\gamma}{A}=\ell
$$

Thus, honest taxpayers receive utility

$$
u_{h}=\frac{1}{2} \frac{(1-\gamma)^{2}}{A}
$$

If the taxpayer decides to evade taxes, she solves utility as

$$
\max _{\ell}(1-\mu) \ell+\mu(1-\gamma(1+\pi \phi)) \ell-\frac{1}{2} A \ell^{2}-E
$$

when we use $\mu$ as derived in Section II.A, as the probability of an audit. From the first order

where the transfers to the consumers would be lump-sum, leaving the first order conditions below unchanged. We omit this for brevity.

${ }^{7}$ The linear quadratic functional form and the restriction on $\gamma$ ensures that we do not have labor supply induced Laffer effects. Without compliance effects increasing taxes would increase tax revenues in this setup.

${ }^{8}$ The auditing mechanism is as described in Section II.A.

${ }^{9}$ The results do not change if heterogeneity is displayed in the cost of tax evasion, E. This could be interpreted as differring access to tax evasion techniques.

${ }^{10}$ If we did not impose a constraint on the mean of $\phi$, either that or $\pi$ would be redundant. 
condition and the requirement that $\ell \geq 0$,

$$
\ell=\left(\frac{1-\mu \gamma(1+\pi \phi)}{A}\right)^{+}
$$

where $(\square)^{+}=\max (0, \square)$ denotes the positive part of a quantity.

Similarly to (8), tax evaders can expect utility

$$
u_{e}=\frac{1}{2} \frac{\left((1-\mu \gamma(1+\pi \phi))^{+}\right)^{2}}{A}-E
$$

Taking $\mu$ as exogenous and using (4), the taxpayer will cheat if and only if

$$
\frac{1}{2} \frac{\left((1-\mu \gamma(1+\pi \phi))^{+}\right)^{2}}{A}-E \geq \frac{1}{2} \frac{(1-\gamma)^{2}}{A}
$$

Solving condition (12) is simplified by noting the following. If the $(\square)^{+}$term is zero, that implies that the labor supply of the tax evader is zero. This in turn implies that the left hand side of equation (12) is negative, while the right hand side is positive. In other words, condition (12) is not satisfied for sure when the $(\square)^{+}$term is zero. Hence, we can focus on the case when the term is positive.

Condition (12) then holds if and only if

$$
1-\mu \gamma(1+\phi \pi) \geq \sqrt{(1-\gamma)^{2}+2 A E}
$$

which is equivalent to

$$
\phi \leq \frac{1}{\pi}\left(\frac{1-\sqrt{(1-\gamma)^{2}+2 A E}}{\mu \gamma}-1\right) \equiv \bar{\phi}(\mu, \gamma, \pi)
$$

which gives unique condition in terms of $\phi$, when the taxpayer pays taxes as prescribed.

Before continuing to solve the model, it is worth to explore the comparative statics of the $\bar{\phi}$ threshold. The threshold is the lower (i.e. less taxpayers evade), if the equilibrium probability of an audit is higher, $\partial \bar{\phi} / \partial \mu<0$. Also, less taxpayers evade, if tax evasion is costlier, $\partial \bar{\phi} / \partial E<0$, and if the objective punishment is higher, $\partial \bar{\phi} / \partial \pi<0$. More interestingly, less taxpayers evade, if the disutility of work is higher $\partial \bar{\phi} / \partial A<0$. The intuition is, that higher disutitiliy decreases income, hence the gains from evasion. Finally, more taxpayers evade the higher the tax rate is as expected, $\partial \bar{\phi} / \partial \gamma>0 .{ }^{11}$ Intuitively, the higher the taxes the more is to be gain from evading them.

${ }^{11}$ The derivation is in Section V.A. 


\section{Equilibrium and comparative statics}

Using the previous results, the total mass of agents evading taxes for a given $\mu$ is

$$
\tilde{\lambda}(\mu ; \gamma, \pi)=F(\bar{\phi}(\mu, \gamma, \pi))=F\left(\frac{1}{\pi}\left(\frac{1-\sqrt{(1-\gamma)^{2}+2 A E}}{\mu \gamma}-1\right)\right)
$$

It is easy to see that $\lambda(\mu)$ is decreasing in $\mu$ as expected.

We can also derive the total mass of tax evaders using the tax authority resource constraint equation (2), again as a function of $\mu$

$$
\hat{\lambda}(\mu)=\frac{\tau / \mu-\tau_{h}}{\tau_{e}-\tau_{h}}
$$

In equilibrium these two measures of mass of tax evaders are the same, hence we define the equilibrium $\mu$ such that

$$
\widetilde{\lambda}(\mu ; \gamma, \pi)=\hat{\lambda}\left(\mu ; \tau, \tau_{h}, \tau_{e}\right)
$$

The right hand side converges to $\infty$ when $\mu \rightarrow 0$, and when $\mu=1$, equals to

$$
\frac{\overbrace{\tau-\tau_{h}}^{<0}}{\underbrace{\tau_{e}-\tau_{h}}_{>0}}<0
$$

Since both sides are decreasing in $\mu$, this curve may have multiple intersections. If $\tilde{\lambda}$ is a continuous function of $\mu$ (this holds if and only if the distribution $F$ is continuous), the two curves have an odd number of intersections (at least one), since $\hat{\lambda}$ starts above (at $\mu=0$ ) but ends below (at $\mu=1$ ) the function $\lambda$. For simplicity, we will consider the case when the two curves intersect only once, eliminating multiple equilibria (which are briefly explored in Section V.B). This of course requires that at the point of intersection, the slope of the tax evaders curve $(\tilde{\lambda})$ is smaller than the slope of the audit capacity curve $(\hat{\lambda})$ in absolute value.

Changes in parameters move the audit capacity and tax evaders curves, and the fact that each one of the parameters $A, E, \pi, \gamma, \tau, \tau_{h}, \tau_{e}$ affect only one of these curves makes comparative statics easier. First we discuss the behavior of the $\hat{\lambda}$ curve, which establishes the audit capacity required for a given audit probability. From (16), note that only the ratios $\tau_{h} / \tau$ and $\tau_{e} / \tau$ matter. Increasing $\tau$ but leaving $\tau_{h}$ and $\tau_{e}$ constant moves this curve upwards, moving the intersection of the two curves to the right (higher audit probability) and downwards (fewer tax evaders). Increasing $\tau_{e}$ or decreasing $\tau_{h}$ (ceteris paribus) would of course have the opposite effect, making tax evasion harder to persecute in relative terms.

Second, using the comparative statics for $\bar{\phi}$ from the end of Section II.B, we can also explore the changes in the $\tilde{\lambda}$ curve (tax evaders as a function of audit probability), since $F$ is a strictly monotone increasing function, $\tilde{\lambda}(\ldots)=F(\bar{\phi}(\ldots))$ inherits the properties of the comparative 
statics. For example, increasing the tax rate $\gamma$ moves the $\tilde{\lambda}$ curve upwards, leading to more tax evaders and lower audit probability. Increasing $A, E$ or $\pi$ moves the curve downwards, resulting in fewer tax evaders and higher audit probability.

Qualitatively these features of the model are consistent with out intuition, but it remains to be seen whether the results are significant when we actually calculate equilibria, which we deal with in the next section.

\section{ILLUSTRATIVE EXAMPLE}

The previous sections has solved the model in general parametric terms. In this section, we turn to parametrize the variables and use numerical techniques to illustrate the results. We undertook the analysis with the following parameter values: $A=1, E=0.1, \gamma=0.115, \pi=3, \tau=1$, $\tau_{h}=20$ and $\tau_{e}=50$. The interpretation of the parameters is straightforward. For instance, we assumed that tax evaders' punishment amounts to three times the evaded taxes, and if everyone was honest, the tax authority would be able to audit $1 / 20=5 \%$ of the population. The parameters have been chosen to be both realistic and demonstrate the revenue increasing effect to tax rate cuts. ${ }^{12}$ Furthermore, we assumed that $\phi$ is distributed lognormally such that the underlying normal distribution has unit variance. ${ }^{13}$

Figure (1) shows the equilibrium at the intersection of equations (16) and (17). As discussed in Section (II.C) the system always has at least one solution, and we concentrate on cases where this solution is unique (relegating the case of multiple equilibria to the appendix). In the equilibrium in Figure (1) somewhat less than $34.6 \%$ of taxpayers evade taxes and the likelihood of a tax authority audit is around 3.3\%. The economy described on Figure (1) shows roughly twice as large tax gaps as the $16.3 \%$ IRS (2006) estimate for the United State. Thus, our example shows a country with significant, but far from unrealistic tax compliance problems.

The first question is what happens in equilibrium when the tax rate changes. Figure (2) highlights the response to moderate tax rate changes. The tax rate of the original equilibrium is $11.5 \%$. We investigate what happens when the tax rate is changed by $\pm 1 \%, 11.615 \%$ and $11.385 \%$. When the tax rate is increased by $1 \%$, the $\widetilde{\lambda}(\mu)$ curve, which denotes the number of evaders, shifts to the right. The audit capacity curve $\hat{\lambda}(\mu)$ as the resources of the tax authority are left unchanged, does not shift. In the new equilibrium, $8.9 \%$ of taxpayers evade taxes. In other words, a $1 \%$ tax rate cut results in a $40 \%$ increase in tax compliance. Similarly, if the tax rate is increased the $\widetilde{\lambda}(\mu)$ curve shifts to the left. In the new, higher tax equilibrium $51.3 \%$ of taxpayers evade taxes.

Figure (3) shows the case for much larger, 5\% changes in the official tax rates, to $12.07 \%$ and

${ }^{12}$ Of course, the parameters could certainly be further calibrated to fit a partcular country case or legal setup. However, these parameters provide a good starting point for analysis and the model's prediction do not depend on the parameter choice. In order to check robustness, we perfomed the calculation with variations in the parameter values, which left the main results intact.

${ }^{13}(5)$ pins down the mean. 


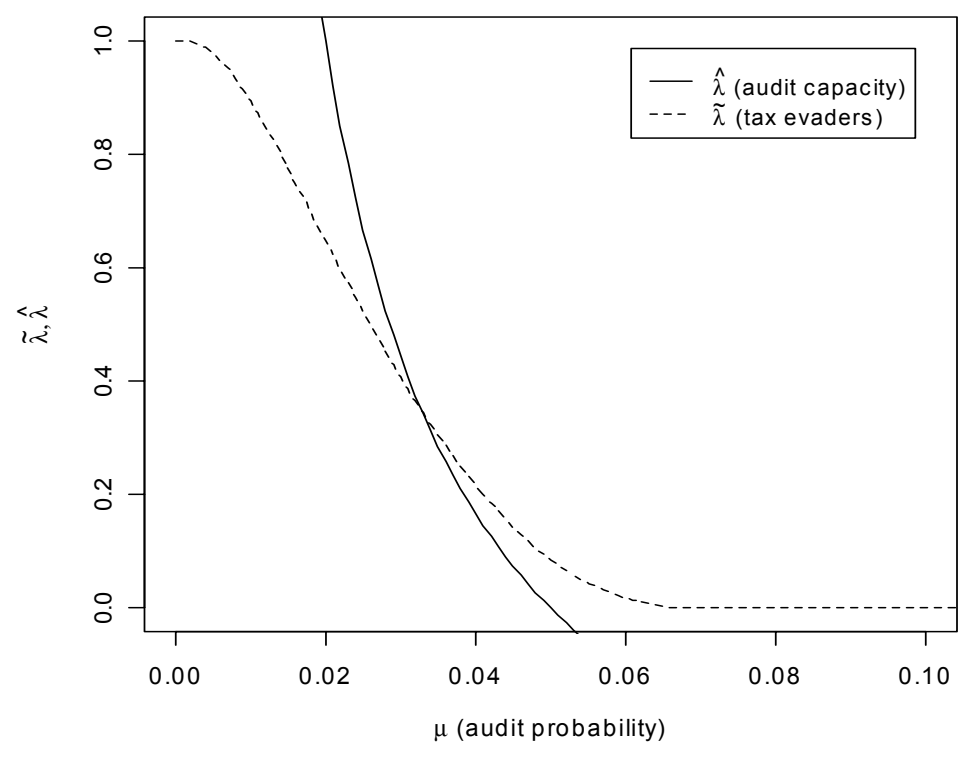

Figure 1: Equilibrium

10.92\%. This large change chart helps illustrating the strong non-linearities of the model. The large tax rate cut almost completely eliminates tax evasion. In fact, it is evident from a cursory look on the chart, that a much smaller rate cut could accomplish that. A large tax rate hike, however, would raise non-compliance to $77.4 \%$, by almost doubling it. The strong differences between the two equilibria show the need for careful empirical investigations. Reactions to tax changes might look as strong as shifts between multiple equilibria, whereas they might be only the consequences of very strong spillovers and resulting non-linearities.

Figure (4) and (5) highlight how changes in tax enforcement affect tax compliance. Figure (4) shows the case when the tax authority's resource (remember $\tau=1$ ) is changes by $5 \%$. If the tax authority's time endowment is increased by $5 \%$ (to 1.05 ), the audit capacity curve, the $\hat{\lambda}(\mu$ ) curve, shifts to the right. (Now, the tax evaders curve, the $\widetilde{\lambda}(\mu)$ curve does not move.) In the new equilibrium evasion is lowered to $23.9 \%$, as expected. Weakening of the tax authority increases compliance through shifting the audit capacity curve to the left. In our example tax evasion rises to $43.6 \%$.

Figure (5) highlights the model's non-linearities by examining stronger changes in the enforcement power of the tax authority. A 50\% increase in the tax authority's time endowment (to 1.5) eliminates tax evasion completely. A 50\% decrease in tax authority resource more than doubles non-compliance, and $87.7 \%$ of citizens evade taxes.

Changes in tax authority time endowment has very similar effects to tax rate cuts, though as the figures show, they work through different channels. Most importantly, the result highlights the potential trade-offs between improving tax enforcement and cutting official tax rates. Depending 


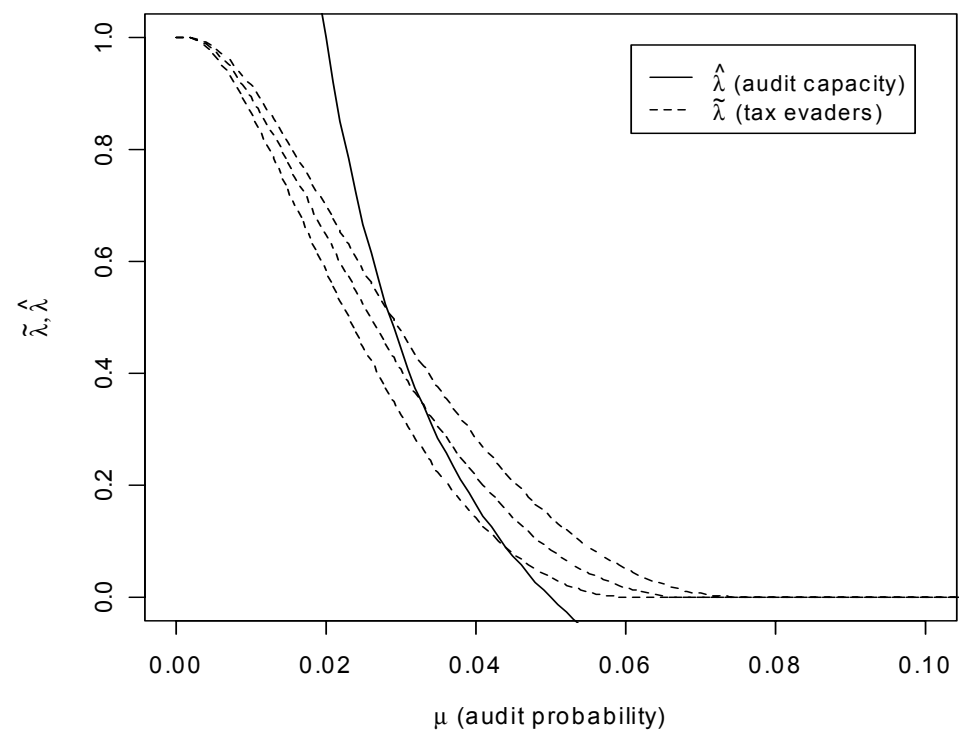

Figure 2: Tax rate change: 1 percent

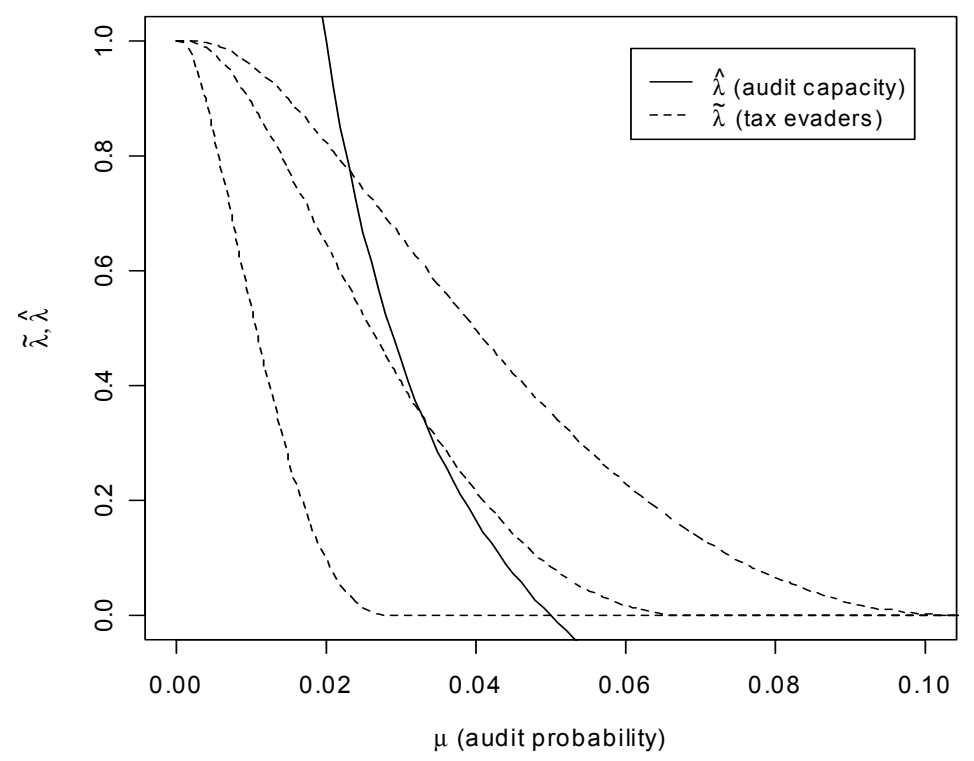

Figure 3: Tax rate change: 5 percent 


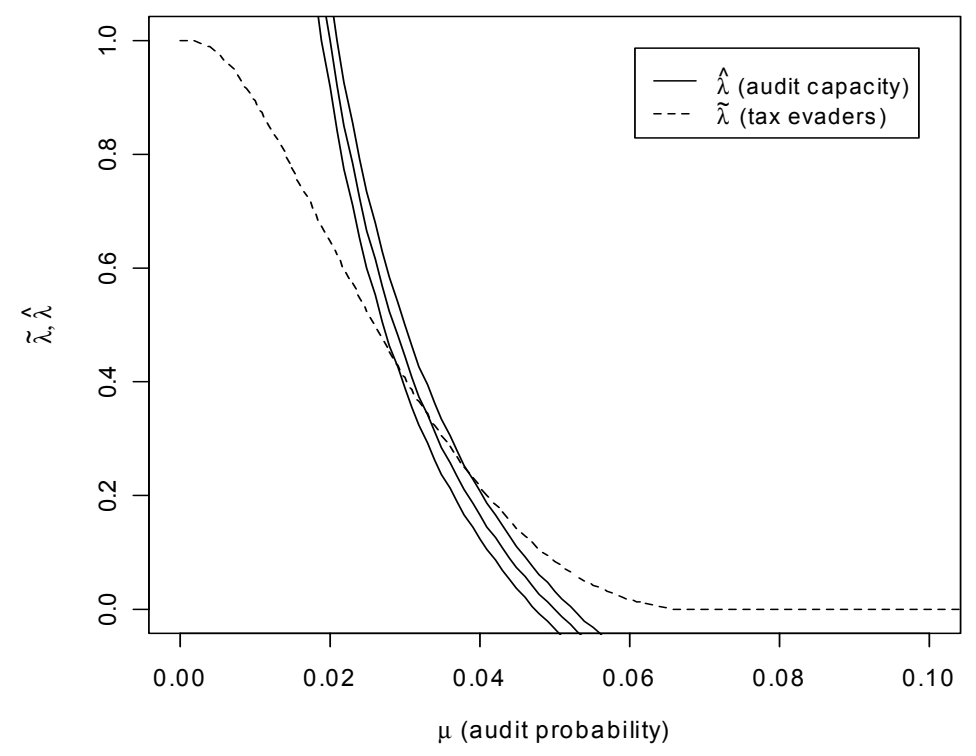

Figure 4: Changing tax authority time endowment $(\tau)$ : 5 percent

on the circumstance tax rate cuts might be preferred over strengthening enforcement. The necessary extensions to evaluate these trade-offs (and the welfare effects) are straightforward and omitted here.

The most important question is, however, how tax rate cuts affect tax revenues. Figure (6) charts tax revenues as a function of the official tax rate. The chart depicts a Laffer curve: Tax rate increases initially increase tax revenues until the tax rate reaches $12 \%$. The Laffer effect is coming from increased compliance and not from labor supply responses as Figure (7) shows. On Figure (7) we depict the changes in the implied tax revenues, which is the revenue that taxpayers would pay if they were all honest. As evident from the figure, the tax revenue is increasing when $\gamma<1 / 2$. Hence, labor supply changes do not cause the Laffer effect. Rather changes in tax compliance drive the results: The percentage of honest taxpayers falls dramatically when the tax rate exceeds $12 \%$ (right scale).

Finally, the Laffer curve also highlights that tax rate cuts in this framework do not amount to tax cuts. Effective tax rates can increase when the official tax rate is cut. In fact, this is exactly what causes the Laffer effect here. Moreover, tax rate cuts raise effective taxes only by making tax evaders pay more taxes. Honest taxpayers will end up paying less taxes, while the government's tax revenues increase.

\section{Conclusion}

The model shows that tax rate cuts can increase tax compliance so much that tax revenues increase in response. Tax rate cuts can affect tax revenues through two main channels: Affecting 


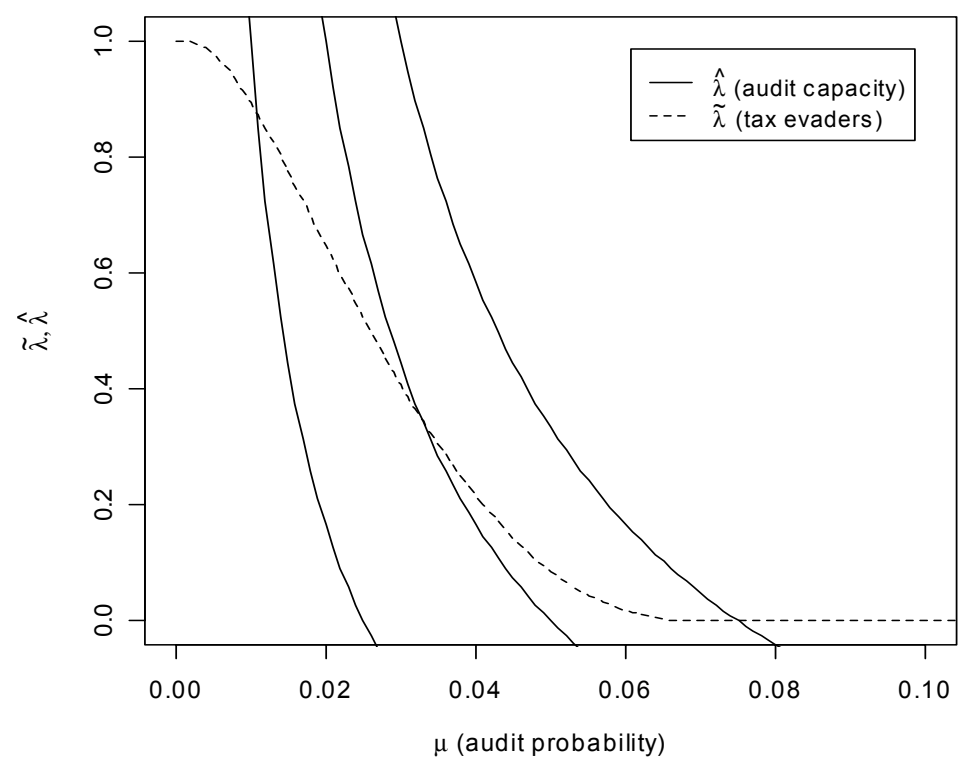

Figure 5: Changing tax authority time endowment $(\tau)$ : 50 percent

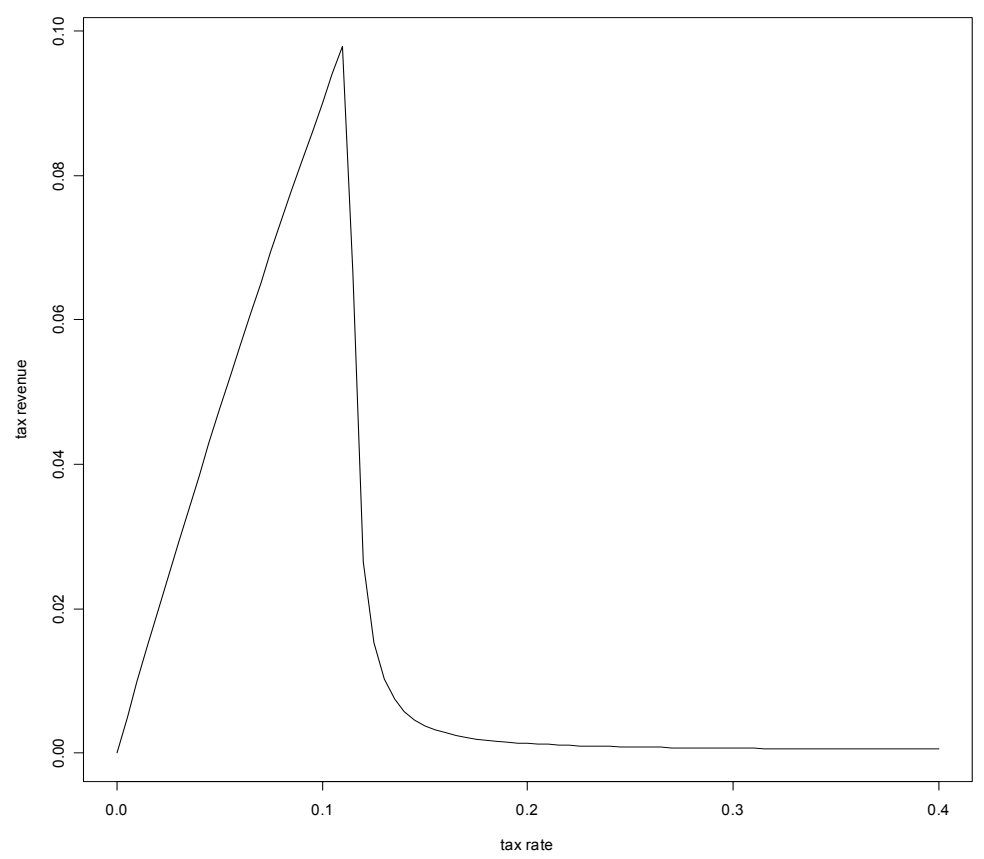

Figure 6: Laffer curve 


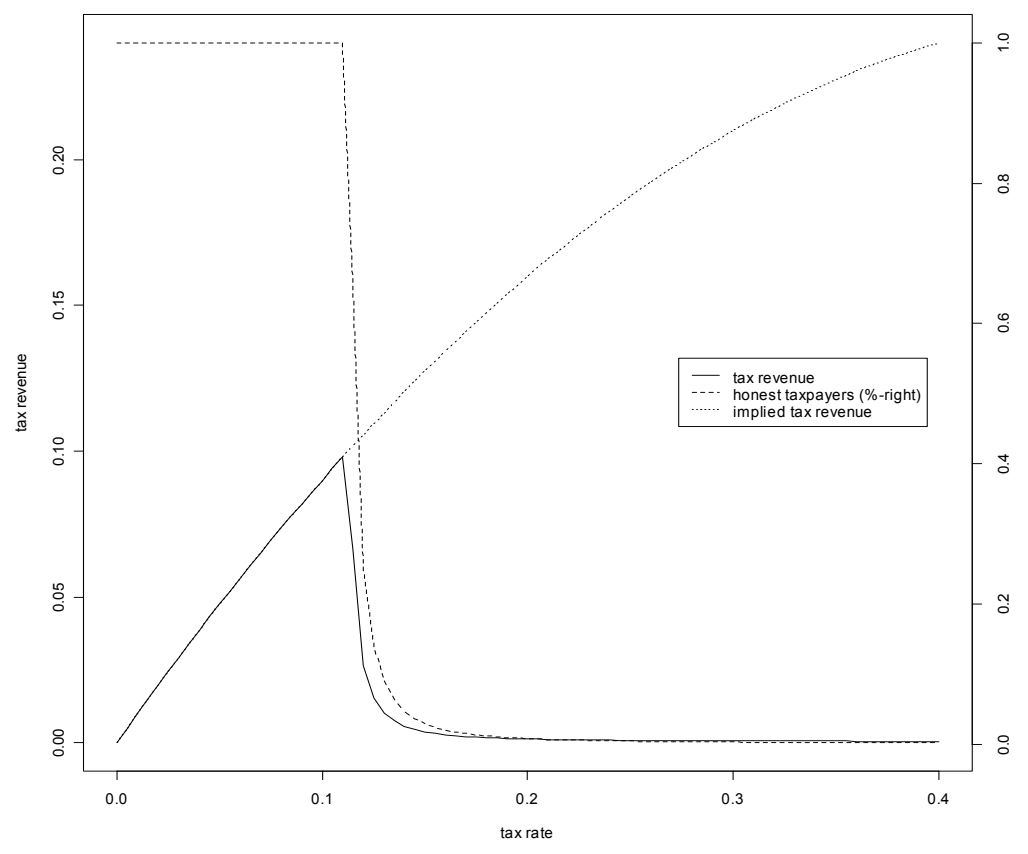

Figure 7: Laffer curve decomposition

the tax base or affecting compliance with the tax rules. The first channel is much discussed in the framework of the classical supply side literature. This paper explores the second, much less understood compliance channel in a macroeconomic framework.

The model's findings are consistent with what happened in Russia. This research has been motivated by the Russian experience, where tax rate cuts have increased both tax revenues and effective tax rates. The fact that measures of compliance also have shown marked increase further hints at the appropriateness of the example. However, the aim of this paper is not to explain the Russian flat tax experiment, but to address a general economic point relevant much more widely. Evaluating the Russian tax cuts is clearly an empirical question with many other potential explanations. ${ }^{14}$

The theoretical model is potentially useful to think about tax policy. Most importantly, it identifies when this compliance based Laffer effect can arise, i.e. when tax rate cuts can increase revenues even on the short run. It is crucial to have medium strength tax authorities compared to the prevailing official tax rates. If tax authorities are relatively strong (at least relative to the prescribed

${ }^{14}$ First, the tax reform coincided with the reform of tax collection. Obviously improved tax collection could also have increased tax revenues even with lower official tax rates. Second, according to official data the share of labor income has started to increase (and recover from the 1998 low point) around 2001. Hence, it might be that compliance effects were dominated by labor income increases. Third, income shifting from corporate to personal income could have also been responsible for the increasing tax base. These explanations are highlighted and discussed in detail in Ivanova, Keen and Klemm (2005). 
taxes), then compliance is the best strategy for the overwhelming majority of taxpayers. Tax rate cuts or increases do not change compliance much, as audits ensure it. Similarly, if the tax authority is relatively weak, no tax rate changes will induce compliance. With medium level tax authority strength, however, tax rates can have a pivotal role.

Furthermore, linking tax authority strength to official tax rates highlights the general applicability of the model. Three cases could be highlighted. First, countries with high official tax rates and relatively weaker tax authorities, such as some of the transition economies, might benefit from tax rate cuts and improving compliance. Second, the model might be also relevant for countries with high tax rates, even if tax enforcement seems to be strong in absolute terms. Third, low tax countries which have particularly weak tax enforcement could also think about improving tax compliance via tax rate cuts.

The paper is also useful in highlighting trade-offs between improving tax enforcement (through more resources or higher punishments) versus improving tax compliance (through tax rate cuts). The model can be used for welfare analysis in comparing the different options. Extending the model and exploring the dynamic effects would be especially interesting. The optimal timing of compliance and enforcement measures might be complex. For instance, it could potentially be useful to rely initially on compliance effects while the tax enforcement capacity is built up.

The model can also be used to design future empirical studies. Empirical studies have mostly focused on the labor supply effect of tax rate cuts (i.e. on the tax base effects). The traditional literature reviewed in Heckman (1993) and the challenging study in Feldstein (1995) all focus on labor supply effects. Even more recent studies, such as Coenen et al (2007) or Trabandt and Uhlig (2006), continue to investigate the labor supply channel for potential Laffer curves. Following the logic of this paper, compliance effects could be incorporated into empirical papers. In principle, studies like Fisman and Wei (2004) could directly identify the tax base (labor supply) and the compliance channel of the Laffer effect they find.

In conclusion, the paper developed an endogenous tax compliance model which explains how tax cuts can increase tax revenues without increasing labor supply much. Yet, this is only a first step: there is much left for future research. The most important step seems to be to expand the model to several periods and investigate the dynamic implications more closely. Most importantly, a finer distinction between short run and long run effects of labor supply and tax compliance would be highly useful for policy making. Further empirical research is needed to identify the exact conditions under which tax cuts can increase compliance sufficiently to increase tax revenues. Answering these questions would not only benefit our understanding of tax policies, but also help guide economic policy. 


\section{APPEndix}

\section{A. Comparative statics for $\bar{\phi}$}

First notice that under our assumptions $\gamma<1 / 2, A, E>0$

$$
\gamma \leq \frac{1}{2}+A E
$$

For making the algebra more transparent, let $\psi$ denote $\sqrt{(1-\gamma)^{2}+2 A E}$. Then

$$
\frac{\partial \bar{\phi}}{\partial \gamma}=\frac{1}{\pi} \frac{\partial}{\partial \gamma}\left(\frac{1-\sqrt{(1-\gamma)^{2}+2 A E}}{\gamma \mu}-1\right)=\frac{\frac{1-\gamma}{\psi}-\frac{1-\psi}{\gamma}}{\gamma \mu \pi}
$$

We can rearrange the denominator as

$$
\frac{1-\gamma}{\psi}-\frac{1-\psi}{\gamma}=\frac{\gamma-\gamma^{2}-\psi+\psi^{2}}{\gamma \psi}=\frac{(\psi-\gamma)(\psi+\gamma-1)}{\gamma \psi}
$$

Now $\psi+\gamma-1 \geq 0$ is equivalent to

$$
1-\gamma \leq \sqrt{(1-\gamma)^{2}+2 A E}
$$

which always holds because $A, E>0$.

As for the other term, $\psi \geq \gamma$ is equivalent to

$$
\begin{gathered}
\sqrt{(1-\gamma)^{2}+2 A E} \geq \gamma \quad \Leftrightarrow \\
(1-\gamma)^{2}+2 A E \geq \gamma^{2} \quad \Leftrightarrow \\
1-2 \gamma+2 A E \geq 0 \quad \Leftrightarrow \\
\frac{1}{2}+A E \geq \gamma
\end{gathered}
$$

which is (18). 


\section{B. Multiple equilibria}

The model can produce multiple equilibria as it was discussed in Section II.C. Here we only change the underlying normal distribution's variance to 0.5 , and illustrate the results on Figure (8).

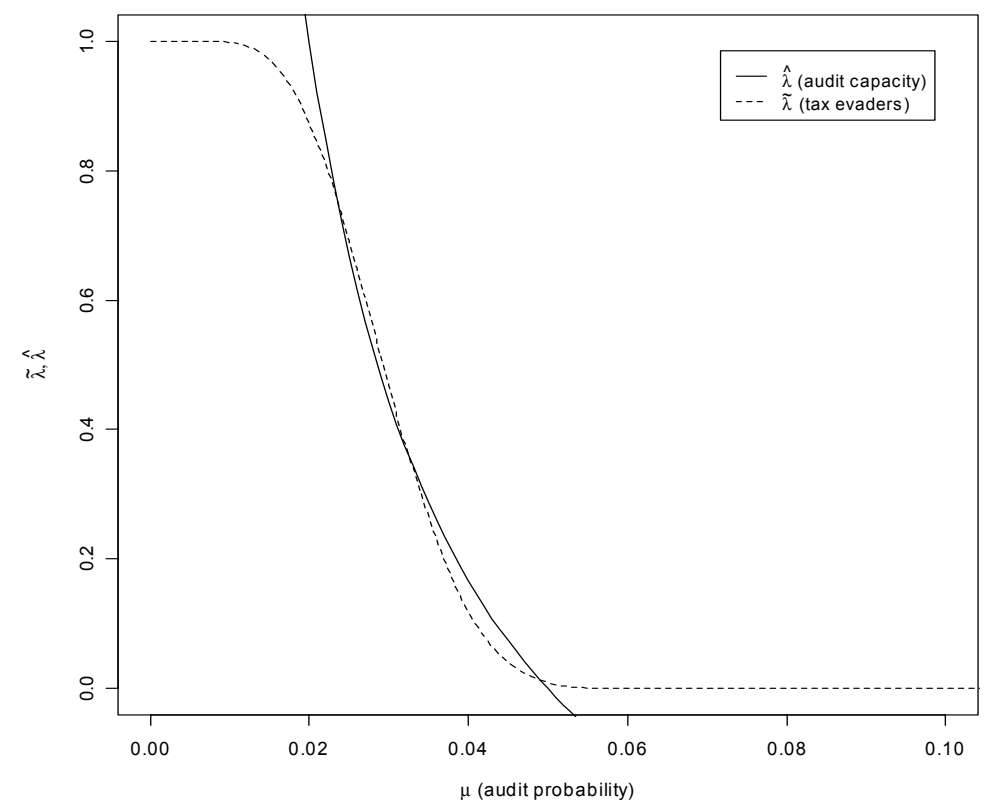

Figure 8: Multiple equilibria

Hence, the model is able to explain equilibrium switching patterns in theory. Intuitively, if agents are very similar, then marginal tax changes can lead to equilibrium switching. This simpler point is not pursued here in detail. However, an earlier version of this paper has explicitly derived how tax rate cuts can lead to equilibrium switching and increasing tax revenues and available upon request.

The figure also highlights that potentially perverse results can also arise depending on the relative slope of the audit capacity and tax evaders curves. Comparative static exercises with parameter setup used in Figure (8) show that in the middle equilibrium increasing audit capacity would increase tax evasion. (This actually might also be seen without undertaking the formal exercise.) However, in the other two equilibria comparative statics are as expected. 


\section{REFERENCES}

[1] Allingham, Micheal G. and Agnar Sandmo (1972) Income Tax Evasion: A theoretical Analysis

[2] Andreoni, J., B. Erard and J. Feinstein (1998) Tax compliance, Journal of Economic Literature, 36, 818-60.

[3] Bassetto, Marco and C. Phelan (2006) Tax Riots, WP 2006-04, Federal Reserve Bank of Chicago.

[4] Besley, T., I. Preston and M. Ridge (1997) Fiscal anarchy in the UK: modelling poll tax noncompliance, Journal of Public Economics 64, pp 137-152

[5] Brown, E. R. and M. J. Mazur (2003) The National Research Program: Measuring Taxpayer Compliance Comprehensively, mimeo

[6] Chua, D. (2003). 'Tax reform in Russia', pp. 77-98 in D. Owen and D. Robinson (eds.), Russia Rebounds, International Monetary Fund, Washington, DC.

[7] Coenen, G., P. McAdam and R. Straub (2007) Tax reform and labour-market performance in the euro area: a simulation-based analysis using the New Area-Wide Model, ECB Working Paper No. 747, April 2007

[8] Clotfelter, C.T. (1983) Tax evasion and taxrates, Review of Economics and Statistics 65: 363-373

[9] Cowell, Frank A. (1990) Cheating the government: the economics of evasion, Cambridge, Mass. : MIT Press

[10] Engel, E.E. and J.R. Hines, Jr (1999). Understanding tax evasion dynamics, NBER Working Paper 6903.

[11] IRS (2006) Written testimony of commissioner of internal revenue Mark Everson before the Senate Committee on the Budget on the tax gap and how to solve it, February 15, 2006

[12]Fisman, Raymond and Shang-Jin Wei (2004) Tax rates and tax evasion: Evidence from "missing imports" in China, Journal of Political Economy, 2004 vol 112, no 2. pp 471-491

[13]Feldstein, M. (1995) The effect of marginal tax rates on taxable income: A panel study of the 1986 Tax Reform Act, Journal of Political Economy, 103, 551-72.

[14]Feldstein, M. (1999) Tax Avoidance And The Deadweight Loss Of The Income Tax, The Review of Economics and Statistics, MIT Press, vol. 81(4), pp 674-680, November.

[15] Goolsbee, Austan (1999) Evidence on the high-income Laffer-curve from six decades of tax reform, Brookings Papers on Economic Activity, (2), pp. 1-64.

[16] Gruber, J. and E. Saez (2002) The eleasticity of taxable income: evidence and implications, Journal of Public Economics, 84, pp 1-32

[17] Heckman, J. (1993) What has been learned about labor supply in the past twenty years? American Economic Review, 83, pp 11-121.

[18] Ivanova, Anna, Michael Keen and Alexander Klemm (2005) The Russian Flat Tax, Economic Policy, July: pp 397-444.

[19] Keen, Michael, Yitae Kim, and Ricardo Versano (2007) The "Flat Tax(es)": Principles and Evidence, forthcoming in International Tax and Public Finance

[20] Sah, K. R. (1991) Social Osmosis and Patterns of Crime, Journal of Political Economy, Vol 
99, no 6 pp 1272-1295

[21] Schneider, F. (2002) The Size and Development of the Shadow Economies of 22 Transition and 21 OECD Countries, IZA Discussion Paper, No. 514

[22] Enste D. and F. Schneider (2000) Shadow economies: Sizes, causes, and consequences, Journal of Economic Literature, 38, 77-114.

[23] Slemrod, J. (2001). 'A general model of the behavioral response to taxation', International Tax and Public Finance, 8, 119-28.

[24] Slemrod, J. and S. Yitzhaki (2002) Tax avoidance, evasion and administration, pp. 1423-70 in A. Auerbach and M. Feldstein (eds.), Handbook of Public Economics, North-Holland, Amsterdam.

[25] Yitzhaki, S. (1974) A note on Income Tax Evasion: A Theoretical Analysis, Journal of Public Economics, 3, 201-2.

[26] Tanzi, V. and P. Shome (1993) A Primer on Tax Evasion, IMF Working Paper, WP/93/21

[27] Trabandt, M. and H. Uhlig (2006) How Far Are We From the Slippery Slope? The Laffer Curve Revisited, CEPR Discussion Papers 5657, C.E.P.R. Discussion Papers. 